\title{
SENTIR Y TENER SENTIDO
}

\author{
Humberto Malavassi Calvo 1
}

\section{Resumen}

Este artículo plantea, mediante una pequeña reflexión, que el desprestigio que tenemos los educadores, que nos hace aparecer como los únicos responsables del rendimiento académico y la formación humana, no es cierto; los actores del proceso educativo, no son sólo los educadores, sino los gremios, las instituciones superiores de educación, las instituciones gubernamentales y los hogares, principalmente.

Mediante una pequeña experiencia con 93 estudiantes de décimo del Conservatorio Castella que presentaban una conducta agresiva e irrespetuosa hacia la institución, se trabajaron cuatro sesiones, con la ayuda de una colega de la Universidad Nacional, para explorar, a manera de diagnóstico, cuál podría ser la causa de la resistencia hacia los profesores y la indisciplina que existía en esos grupos.

Se les pasó un cuestionario y se realizó una actividad con un trabajo más personalizado, para que cada estudiante pudiera manifestar abiertamente cuáles eran sus inquietudes e incomodidades.
Al final de este diagnóstico, manifestaron, de una u otra manera, que la responsabilidad de la educación es de todos, y que si no le damos sentido, ni sentimiento a nuestros actos, estaríamos fomentando y promoviendo un clima cada vez más estéril y distante entre los diferentes actores del proceso educativo, pues se viviría en un mundo reservado a promedios, contenidos y memoria, en vez de desempeño y autorrealización.

\section{Abstract}

By means of a brief reflection, the author explains that the low reputation teachers have, which has for so long blamed teachers for the poor academic performance and humanistic education of our youth, is totally undeserved. Teachers are not the only actors responsible for the education process; unions, higher education institutions, government agencies and, mainly, the homes, are also involved in the process.

An activity was carried out with 93 tenth graders from the Conservatorio Castella High School. The students had been

\footnotetext{
1 Bachiller en Enseñanza de las Artes Musicales, Universidad de Costa Rica. Licenciado en Música con énfasis en Educación Musical, Universidad Nacional. Magíster en Educación con Mención en el Aprendizaje del Español como Lengua Extranjera, Universidad Nacional. Actualmente Director de la División de Educología. CIDE, Universidad Nacional.
} 
showing an aggressive, disrespectful attitude towards the school. Along with another colleague from Universidad Nacional, four sessions were devoted to diagnosing possible causes for their rebellion toward their teachers and for their indiscipline. The students answered a questionnaire and also received individual attention so that they could talk openly about their concerns and unrest.

The students claimed that, the education process is everybody's concern, and if it lacks meaning, or if teachers are not committed with their actions, they would be fostering a growing sterile, distant atmosphere among all the actors involved in the process. Then, education would be reduced to complying with GPAs, contents and memory rather than promoting good performance and self-realization.

Descriptores: educación, música, autorrealización, disciplina, aprendizaje, sentido, constancia.

$\mathrm{M}$ e gustaría hacer una pequeña reflexión en cuanto al desprestigio que tenemos los educadores en este país, puesto que se nos hace aparecer como los únicos responsables del rendimiento académico y la formación humana. Con este título "sentir y tener sentido", me refiero a algunos factores que determinan que la culpa de ese desprestigio la deberíamos compartir muchos actores del proceso educativo, no sólo los educadores.

A la hora de construir el currículo por medio de los planes y programas, es necesario tomar en cuenta la formación integral de los y las estudiantes, las actitudes y valores, las habilidades y las destrezas que queremos que desarrollen.

Cuando en la elaboración de los planes y los programas surgen las siguientes preguntas: qué, cuándo, dónde, cómo, quién y para qué, pareciera que las respuestas ya están dadas de antemano por alguien a manera de obligatoriedad e imposición o aquiescencia. Una cosa es que la educación sea obligatoria y otra es que el proceso para llevarla a cabo sea único y obligatorio.

El alumno, generalmente, no se desenvuelve en un ambiente propicio donde sienta lo que está haciendo, a manera de disfrute y, sobre todo, que le encuentre sentido a las cosas según su fundamento e importancia. Los posibles pasos que tiene que dar para llegar a una meta específica son frecuentemente tediosos y cansados, por no saber a dónde va, a dónde tiene que llegar o cuál es su utilidad a corto o mediano plazo.

Mis años involucrado con el arte, me han enseñado a comprender que la disciplina y la constancia son vitales, porque al hacer tareas, que a uno en principio no le gustan o ocupan demasiado tiempo, luego de realizarlas, toman sentido y son altamente recompensadas en futuras actividades y servirán luego como plataforma o base de otros conocimientos y aplicaciones posteriores. 
Es muy importante para un alumno el saber que los rudimentos de una disciplina artística, entendidos como aquellos ejercicios diarios sumamente repetitivos, que fortalecen el movimiento, la relajación, la respiración, la colocación del cuerpo, la técnica entre otros, son la base y el fundamento de todo aprendizaje y conocimiento para desarrollarse plenamente como artista y ser humano, siempre y cuando el ambiente que prevalezca en ese proceso sea de mucho estímulo y motivación ( términos tan trillados y gastados, cuando no se toman en serio o simplemente, se quedan en el papel en nuestro proceso educativo).

Sería interesante y recomendable desarrollar un concepto de libertad en función de la responsabilidad, para que el estudiante, sobre todo artístico, comience a entender, que lo importante de una materia o carrera, es su desempeño en el proceso, su creatividad y el producto final, tanto individual como colectivo; además, el cumplimiento de materiales, la puntualidad, el estudio de rudimentos, el aporte y su criticidad deberían tomarse más en cuenta que un reglamento interno de disciplina cuyo énfasis pareciera ser nada más el uniforme, las faldas adentro, los zapatos negros, el pelo corto, que no se pueden desacomodar los pupitres, no se puede hablar en clase, no se puede salir entre lección y lección, entre otros. Esto no propicia en el estudiante un clima armonioso, más bien, lo va a estereotipar socialmente y a condicionar a comportamientos poco naturales y uniformes, que luego el alumno no sabe quién es, quién era, quién quiere ser y quién debería ser.

En estos momentos, es muy importante desarrollar, en diferentes espacios académicos, algunos conceptos y sus alcances, para que propicien un cambio de dirección (o simplemente contribuyan a fortalecer la dirección tomada dentro del aula), como lo son: la disciplina, el autocontrol, el manejo de límites, la creatividad, la felicidad, la tolerancia y la autorrealización, en los diferentes espacios artísticos, deportivos y académicos. El fin es lograr, en nuestro quehacer educativo, una auténtica "vivencia", para no pensar dichos espacios como experiencias limitadas a una construcción cerrada entre cuatro paredes, con una pizarra y unos pupitres, con un profesor al frente diciendo lo único que el Ministerio dice que hay que hacer.

Tenemos que enfocar nuestro proceso educativo hacia el alumno, para que éste sienta realmente lo que construye (disfrute) y que le encuentre sentido (tanto de pertenencia, como de aplicación) a lo que está aprehendiendo.

La investigación (más como medio que como fin) debe servir de marco para que las asociaciones gremiales y las autoridades educativas universitarias y oficiales tomen conciencia, acerca del tipo de ser humano que estamos formando y queremos formar. Asimismo, quienes formamos parte de este proceso (estudiantes, padres de familia, docentes, autoridades, gremios y otros actores 
sociales), podamos debatir acerca de los alcances y los resultados en diferentes foros, seminarios y congresos para tomar acciones con lapsos definidos y responsabilidades concretas. De esta manera, sabríamos cuáles áreas fortalecer, para poder invertir más en calidad, que en la cantidad de días y el conocimiento necesarios para desarrollar lo que el o la estudiante necesita, para formarse y desarrollarse como una persona "feliz" y que con su aprendizaje y reflexión, aporte soluciones prácticas a la sociedad.

Estas afirmaciones las hago con motivo de una experiencia vivida en el Conservatorio Castella, ubicado en Barreal de Heredia, debido a la curiosidad que me embargaba escuchar, que había alumnos muy violentos, agresivos e irrespetuosos (una gran mayoría). Desarrollé un trabajo con ellos y con la ayuda de la psicóloga Alexa Jengich, compañera de trabajo de la Universidad Nacional, tratamos de descubrir realmente qué les incomodaba o molestaba o, simplemente, buscar una explicación que pudiera justificar esas conductas negativas que mostraban.

El grupo estaba conformado por tres secciones de décimo año; 93 alumnos aproximadamente con edades entre 16 y 17 años, de ambos sexos, quienes aspiran al siguiente año a graduarse tanto en bachillerato académico, como artístico.

Luego de una primera visita para conocer los estudiantes y explicarles que queríamos trabajar con ellos, conversamos también con algunos de sus profesores y nos manifestaron un gran malestar por ir a esas aulas, además, que los alumnos los sometían a una gran presión negativa a la hora de desarrollar las lecciones y ofrecían una enorme resistencia, que impedía el ritmo habitual de la lección. También, los profesores comentaban acerca de la conducta de esos alumnos, como un problema y nosotros, lo queríamos ver como una consecuencia de otro u otros problemas.

La palabra "problema" se convirtió en un reto, por lo tanto, se procedió a abrir un espacio de investigación, a manera de diagnóstico, entre la Universidad Nacional y el Conservatorio Castella, para estudiar dónde estaría la causa de ese comportamiento y por qué se daba ese efecto. Procedimos a planear una primera etapa, de cuatro sesiones, en las que se pasaría un cuestionario y se realizaría una actividad grupal, que nos permitiera la apertura de un espacio de trabajo más personalizado, en el que ellos pudieran manifestar abiertamente, de una manera más informal, cuáles eran sus inquietudes y sus incomodidades. A la semana siguiente, se les pasó un cuestionario a los alumnos, como una primera etapa, para determinar su percepción en sus diferentes relaciones familiares, sociales, institucionales e individuales, con el fin de llevámosla y socializar, con ellos en otro encuentro, algunas posibles respuestas que revelara el cuestionario. 
Una semana después se realizó la actividad grupal en la que se conjugaron diferentes factores de tipo emocional, de relajación, de libertad y de conocimiento. Esta actividad se realizó en un sitio con suficiente espacio y silencioso, donde los estudiantes estuvieran cómodos y relajados. Se les invitó a escuchar una obra musical de Jan Garbarek cuyo contenido es inspirado en un Officiumun defunctorum de Chistóbal de Morales (c15001553), con acompañamiento de un saxofón soprano. Dicha obra, favoreció el ambiente en el que se encontraban y les permitió relajarse y estar tranquilos. Luego, se les pidió que elaboraran un dibujo y expresaran lo que sentían y necesitaban en sus vidas en ese momento. Los estudiantes exteriorizaron diferentes opiniones, en un clima de respeto y convivenciae incluso, manifestaron, por un lado, la extrañeza y, por otro, la satisfacción de que alguien les proporcionara un espacio, para preocuparse por lo que ellos sentían y querían en sus vidas y, que las únicas actividades que comúnmente recibían eran de carácter obligatorio y la evaluación, eran tan sólo una "medición de contenidos memorizados y punto".

A medida que la actividad grupal se desarrollaba, el filtro afectivo fue bajando hasta llegar a un punto en que la participación fue tan copiosa, que empezaron a entender que no sólo la actividad era para ellos, sino que era de ellos, por lo que la podían dirigir, de acuerdo con su interés, por medio de las inquietudes y los comentarios que expresaban. Los profesores sólo facilitábamos la conducción con preguntas generadoras.
Es muy importante para un alumno el saber que los rudimentos de una disciplina artística, entendidos como aquellos ejercicios diarios sumamente repetitivos, que fortalecen el movimiento, la relajación, la respiración, la colocación del cuerpo, la técnica entre otros, son la base y el fundamento de todo aprendizaje y conocimiento para desarrollarse plenamente como artista y ser humano.

\section{Tenemos que enfocar nuestro} proceso educativo hacia el alumno, para que este sienta realmente lo que construye (disfrute) y que le encuentre sentido (tanto de pertenencia, está aprehendiendo. como de aplicación) a lo que 
La discusión y el diálogo pronto se convirtieron en quejas, disconformidades y reclamos acerca de la falta de espacios para sentirse como personas únicas e inigualables, a las que alguien escuche y aconseje como adolescentes. Sus problemas académicos y personales no encuentran cabida en un mundo reservado sólo a la materia académica, mediante programas, promedios y planes de estudio, cargados de contenidos y dónde son una cifra o un número más, dentro del currículo nacional.

Es importante recalcar que las conclusiones a las que hemos llegado están basadas en un diagnóstico, que se hizo con un cuestionario y una actividad grupal, como una primera etapa, por lo que sería importante darle continuidad a este trabajo, y estimular a nuestros docentes y estudiantes avanzados de la universidad, para que realicen este tipo de actividades; acciones que abran los espacios cualitativos necesarios, para que los diferentes actores del proceso educativo puedan manifestar sus inquietudes y preocupaciones, cuando noten que el proceso está sufriendo alguna alteración negativa hacia la construcción del conocimiento.

Luego de tabular el cuestionario y establecer algunas similitudes de lo expresado en la actividad grupal, podríamos llegar a las siguientes conclusiones preliminares:

- $\quad$ Existe, por parte de los alumnos, la inquietud en cuanto al trato del docente; ellos quieren saber si el trato amable y personalizado depende del Ministerio de Educación o del propio docente.

- No saben cómo entablar un vínculo más cercano con sus padres y hermanos (manifiestan, en muchos casos, que sus relaciones son muy conflictivas o distantes).

- Les preocupa si la educación es una cuestión de suerte, porque mientras algunos profesores ofrecen un espacio más flexible y cercano a sus necesidades en una relación más de amigo y consejero, otros por el contrario, sólo repiten en su forma de vivir y trabajar un modelo estéril y frío cargado de frustraciones y resentimientos, por todo aquello que pudieron haber hecho y nunca encontraron o quisieron encontrar el espacio.

- Les interesa saber cómo enlazar los planes de estudio con toda la información que se maneja fuera del colegio, para no caer en simples modas pedagógicas o epistemológicas y que cuando se habla de algún autor, como Goleman, Gardner, Pérez, Sierra, Carretero, entre otros, podamos los profesores y las autoridades gubernamentales proponer un estudio serio para adaptar y no adoptar ciegamente, algunas posturas filosóficas y pedagógicas que puedan favorecer los diferentes procesos educativos. 
Manifiestan que muchos profesores caen en la trampa de "hagan lo que digo y no lo que hago", es decir, en un doble discurso. No es lo mismo lo que ellos quieren enseñar, cómo quieren enseñarlo y lo que les gusta, y lo que el alumno realmente necesita como herramientas básicas para el buen desempeño laboral y espiritual de acuerdo con sus propias necesidades y su desarrollo en un ambiente crítico, creativo y muy propositivo.

Meses después, cuando se encontraban en quinto año los reunimos en una finca de recreo y les compartimos algunos resultados. En dicha actividad, agradecieron mucho el trabajo que habíamos realizado con ellos y manifestaron que el trabajo, les había ayudado a limar ciertas asperezas con sus compañeros y a sensibilizarse un poco más acerca del rol que debían de desempeñar como estudiantes en el colegio y como hermanos e hijos en el hogar.

Quisiera terminar reafirmando lo dicho por las y los estudiantes, que la responsabilidad de la educación es de todos, y que si no le damos sentido, ni sentimiento a nuestros actos, estaríamos fomentando y promoviendo un clima cada vez más estéril y distante entre los diferentes actores del proceso educativo. Me gustaría citar tres preguntas (a manera de reflexión) que se hace Fernando Savater en su libro El Valor de Educar (1999:28).

“ ¿Cómo van a transmitirse valores morales o ciudadanos sin recurrir a informaciones históricas, sin dar cuenta de las leyes vigentes y del sistema de gobierno establecido, sin hablar de otras culturas y países, sin hacer reflexiones tan elementales como se quieran de la Psicología y la fisiología humana o sin emplear algunas nociones de información filosófica?"

"¿Y cómo puede instruirse a alguien en conocimientos científicos sin inculcarle respeto por los valores tan humanos como la verdad, la exactitud o la curiosidad?"

"¿Puede alguien aprender las técnicas o las artes sin formarse a la vez en lo que la convivencia social supone y en lo que los hombres anhelan o temen?"

La palabra la tendríamos todos los educadores que estemos dispuestos a disfrutar del proceso educativo con mucha creatividad, tanto en su construcción como en su aplicación, para que este "sentir y tener sentido" en nuestros actos, trascienda del aula hacia todos los miembros de la sociedad, de una manera natural, donde el educador en conjunto con estudiantes y la comunidad en general se fortalezcan mutuamente y puedan apoyarse en diferentes instancias; de 
esta forma, se propician los espacios que generan los cambios sociales necesarios y que transforman, en forma gradual, nuestro quehacer cotidiano.

En relación con las autoridades y la sociedad, es importante que conozcan lo que está pasando en las aulas en cuanto a condiciones, número de estudiantes, cantidad de grupos y limitaciones, para que en conjunto se comience un cambio que favorezca el entorno escolar y social en el que vivimos y que sepan atender a tiempo las sugerencias y recomendaciones que hagan los propios estudiantes y docentes, producto de sus experiencias cotidianas y las puedan convertir en retos y transformaciones de la educación por medio de iniciativas y proposiciones creativas.

De este modo, queda muy claro que con sólo ofrecer un espacio a los y las adolescentes, ellos manifiestan su inconformidad por la manera en que se dan los diferentes procesos educativos, ya sea dentro o fuera de las instituciones educativas; sobre todo cuando se cuestionan si el fin de la educación es aprender o sacar buenas notas, pues los resultados que valen son los números y no se mide el desempeño del conocimiento aprehendido; por ejemplo, en el campo artístico, el conocimiento y las destrezas aprehendidas son acumulativas y su producto termina en un escenario o sala de exposiciones, tomando en cuenta además de su aptitud hacia determinada disciplina, su sensibilidad estética, su actitud creativa, crítica y propositiva.

También, queda claro que los educadores no son los únicos culpables de la situación actual de la educación, por lo que estaríamos en deuda con nuestros estudiantes mientras no intentemos, desde las diferentes instituciones, que forman parte en los procesos educativos, proponer una educación más atractiva, ojalá, enfocada a la resolución de problemas en un contexto y que tenga significado para ellos, según su situación familiar y su entorno.

Debe favorecerse un cambio en el currículum desde la práctica de aula, hasta los programas y planes de estudio. Parafraseando lo dicho por el pedagogo español Ángel Pérez: "no estamos en una época de cambios sino en un cambio de época"; refuerza el hecho de que el sistema educativo ya no soporta más parches ni remiendos producto del capricho de los diferentes gobiernos de turno; lo que se necesita es una verdadera reforma a largo plazo con una gran visión de futuro, que pueda poner a este país a la vanguardia, como lo estuvo hace algunas décadas.

Ya lo decía Albert Einstein: "Más vale tener imaginación que conocimiento". 


\section{BIBLIOGRAFÍA}

Pérez, A. (1998). La Cultura Escolar en la Sociedad Neoliberal. Morata. España.

Carrasco, J., García, A. ( 1996). Salamanca. España.

Carretero, M. (1993). Constructivismo y Educación. Aique. Argentina.

Gardner, H. (1994). Educación Artística y Desarrollo Humano. Paidós. México.

Savater, F. (1997). El Valor de Educar. Ariel. España.

Sierra, J. F. (coord.) (2002). Evaluación del Rendimiento, Evaluación del Aprendizaje. Akal. España.

Pérez, A. (1998). La Cultura Escolar en la Sociedad Neoliberal. Morata. España. 